\title{
Generation of Alternating Droplets with Different Viscosities in a Microfluidic Channel
}

\author{
Muhammad SAQIB ${ }^{1}$, E. Yegan ERDEM ${ }^{* 1,2}$ \\ ${ }^{1}$ Bilkent University, Faculty of Engineering, Department of Mechanical Engineering, Ankara \\ ${ }^{2}$ National Nanotechnology Research Center (UNAM), Ankara
}

Geliş tarihi: 27.06.2021 Kabul tarihi: 15.09.2021

\begin{abstract}
Controlled alternating droplet formation in a microfluidic system can lead to an on-chip droplet-based pattern generation. This enables tracking of different samples individually within the same device. For instance, two different liquids can be segmented in a sequenced, repetitive fashion. In this work, we first show pattern generation by using liquids with unequal viscosities. Droplets of water and glycerol solution are generated in an alternating, repetitive fashion by using a microfluidic system with tapered, double $\mathrm{T}$-junction. We also introduce a microsystem that has a mixing unit that generates a controlled sequence of droplets formed by mixing two different liquids on-chip. We believe that this study can have applications such as biological analysis, sorting, cell-based monitoring or on-chip chemical synthesis.
\end{abstract}

Keywords: Microfluidics, Droplet-based flow, Droplet dynamics, Alternating droplets

\section{Mikroakışkan Kanalda Farklı Vizkozitelerde Sıralı Damlacık Oluşturulması}

$\ddot{\mathbf{O z}}$

Mikroakışkan sistemlerde kontrollü ve sıralı damlacık oluşumu çip üzeri damlacık temelli desen oluşturulmasını sağlamak için uygundur. Bu sistemler farklı numuneleri tek bir cihazda ayrı ayrı inceleme fırsatı sunmaktadır. Örneğin iki farklı sıvıdan belli bir sıraya göre damlacıklar oluşturmak mümkündür. $\mathrm{Bu}$ çalışmada önce ikili T-birleşimli kanal geometrisi kullanarak farklı vizkozitelerdeki sıvılardan sıralı damlacık oluşumu gösterilmiştir. Damlacıklar su ve gliserol çözeltilerinden oluşturulmuştur. Ayrıca bu makale kapsamında iki farklı sıvının birleştirilmesi ile sonrasında damlacıkların sıra ile oluşturulmasını sağlamak için de tasarlanmış bir sistem çalışılmıştır. Bu çalışmaların biyoanaliz, tarama, hücre bazlı gözlem, kanal içi kimyasal sentez gibi pek çok uygulama alanı olacaktır.

Anahtar Kelimeler: Mikroakışkanlar, Damlacık temelli akış, Damlacık dinamiği, Sıralı damlacıklar

"Sorumlu yazar (Corresponding author): E. Yegan ERDEM, yeganerdem@bilkent.edu.tr 


\section{INTRODUCTION}

Droplet based microfluidic systems manipulate samples individually without cross contamination which has potential applications in bioanalysis [1], drug delivery [2], single cell monitoring [3], chemical synthesis [4], and several other implementations requiring individual sample handling [5]. The circulating flow profile within the droplets also enables rapid mixing [6] which maintains uniform temperature and residence time for each droplet.

The success of these applications is dependent on the robustness and repeatability of droplet generation. There have been many studies in literature that demonstrate stable droplet generation by using flow-focusing, co-flowing and T-junction geometries. In flow-focusing, the dispersed phase fluid is separated into droplets by the carrier fluid (or continuous fluid) that flows perpendicular to the channel from two opposing sides, eventually breaking the stream into a series of droplets [7]. This method is a simple way of generating droplets, however the flow rate of the continuous phase channels should be identical for obtaining a stable droplet formation. Co-flowing geometries use a nozzle that is aligned with the flow of the continuous phase. The dispersed phase exiting the nozzle is applied shear force by the continuous flow that forms droplets [8]. In T-junction geometries, the dispersed phase and continuous phase meet at a $\mathrm{T}$ shaped junction, perpendicular to each other [9].

Most of the droplet-based microfluidic systems focus on generating droplets from a single source. However, being able to generate droplets from different sources has advantages such as running different analysis on the same device or generating a controlled array for biodetection. For this purpose, Hong et al. used a passive pressure regulator for obtaining alternating droplets formed at two separate T-junctions [10]. Zheng et al. used two merging channels at each dispersed phase side due to which two solutions merge at each end to form a single dispersed phase which generates alternating droplets because of the double T-junction geometry. They used it for protein crystallization experiments but due to limitations of the design they had to ensure that the viscosity of both resulting dispersed phases is identical. In addition to that, the device was limited to generating droplets in the ratio 1:1 [11]. Jin et al. used a standard double T-junction device to generate alternating droplets of dispersed phases having different viscosities but there is no allowance for mixing solution at the dispersed phase inlet channels and this is important since most of the biological applications need some sort of mixing with a primer just before droplet generation so as to be able to time the reaction. Furthermore, in this case as well there is no allowance for generating alternating droplets in a ratio other than 1:1 [12]. Ngo et al. developed a computational model to study the effect of junction angle between the main and side channel and the effect of viscosity ratio between dispersed phase and continuous phase on alternating pattern formation but the effect of difference between viscosities of dispersed phase was not studied [13]. Han et al. performed three dimensional numerical simulations to study the effect of continuous phase viscosity, flow rate ratio, interfacial tension and contact angle on the droplet diameter in a double T-junction device [14]. Yao et al. performed experiments in a T-junction device to study the effect of continuous phase viscosity on droplet generation rate and droplet size [15]. Zhang et al. used a microfluidic oscillator at the continuous phase channel to control alternating droplet generation in a parallel T-junction device which forms droplets of dispersed phases having different viscosities. But the requirement of a microfluidic oscillator hinders the use of this device for generating alternating droplets in a ratio different than 1:1 [16]. Wu et al. used the same concept from Zhang et al. and applied it to the separation of E. coli from blood. Since it is an active method of generating droplets in parallel microfluidics, it makes the system slightly more complicated than a passive method such as the one we have used in the current work [17].

Surya et al. also showed a double T-junction geometry to study alternating droplet formation [18]. For demonstration they used the same type of fluid for droplet formation. Later the usage of 
tapered channels for obtaining a stable alternating droplet formation was shown by Saqib et al. [19]. Here, double T-junction geometry was used, where the channels delivering the droplet phase were tapered. It was explained that the tapered geometry controls the Laplace pressure drop at the junction and assures the formation of droplets in turns. The alternating droplet formation was demonstrated with colored water.

Alternating droplet formation with tapered channels was later used in a study where hybrid nanoparticles were synthesized by merging two alternating droplets formed out of two aqueous solutions [20].

In this work, two droplet sources were delivered from oppositely located channels whereas the continuous fluid flows perpendicular to them. This is the first time that double T-junction has been used to generate droplets of dispersed phases having different viscosities in a ratio $n: 1$ (where $1<\mathrm{n} \leq 3$ ). This enables the analysis of samples that do not need to be chemically or physically identical, making the device more versatile. Since 1:1 mixing has already been demonstrated to conduct a chemical reaction in such a device [20], it could be further used for chemical reactions that require mixing of reactants in an unequal proportion and having no restriction for viscosity matching of both reactants is an additional advantage. We further extend our study to a secondary design that can merge and mix two fluids before alternating pattern formation. This device uses a tapered double Y-junction where first two streams merge and form a droplet at each junction in a synchronized manner. Such a device would be ideal for protein crystallization experiments because it has been discussed by Zheng et al. [11] that the need to have identical viscosity for each dispersed in such a device is a challenge and having to make the viscosity identical by adding another fluid critically reduces the efficiency of the experiments. But in our device, there is no restriction for the viscosity to be identical for the two dispersed phases and we demonstrate that by making the dispersed phase channels tapered we can control the ratio of alternating droplet generation even when the viscosities are unequal.

\section{FABRICATION AND EXPERIMENTAL SET-UP}

\subsection{Fabrication}

The microfluidic system is fabricated by using microfabrication techniques used in the clean room of National Nanotechnology and Research Center (UNAM). First 4-inch silicon wafers are cleaned with acetone, isopropyl alcohol and deionized water. Then wafers are coated with the negative photoresist SU-8 2050 with a thickness of $70 \mu \mathrm{m}$ by spin coating. After this, coated wafers are exposed to UV light for photolithography followed by development. This produces the mold for the microfluidic channel. To produce the actual device, polydimethylsiloxane mixture is poured on this mold and cured at room temperature. Once the curing is over, the microchannels formed in PDMS are separated from the mold. At the final step they are bonded to a glass slide for capping the channels via oxygen plasma treatment. The schematic showing the steps of fabrication is shown in Figure 1.

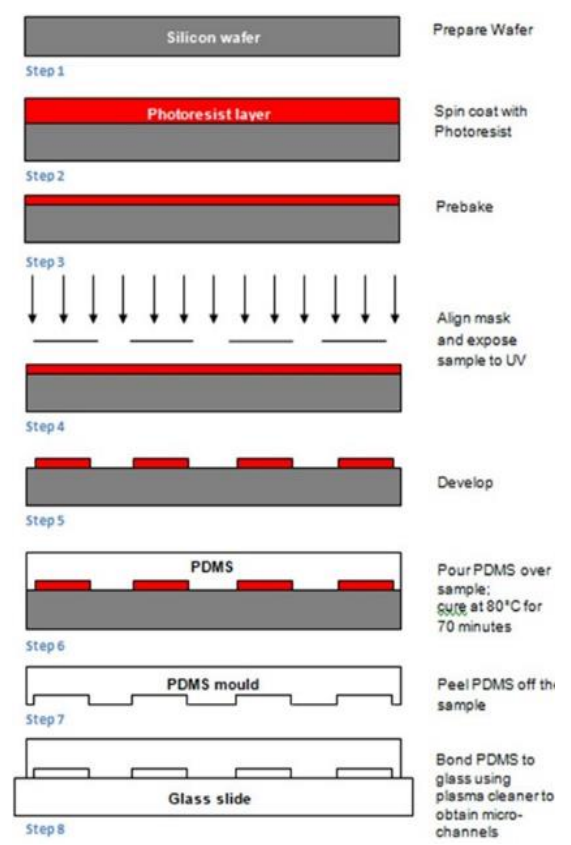

Figure 1. Fabrication steps of the microfluidic device 


\subsection{Experimental Set-up}

The experimental set-up consisted of the microfluidic device, three syringe pumps for the delivery of liquids and a CCD camera attached to a microscope for imaging.

\section{DESIGN}

Two different microfluidic systems are used in this study. The first design used in this work is composed of two opposing microchannels for droplet phase delivery with tapered geometry as described in a previous study [19]. This narrowing
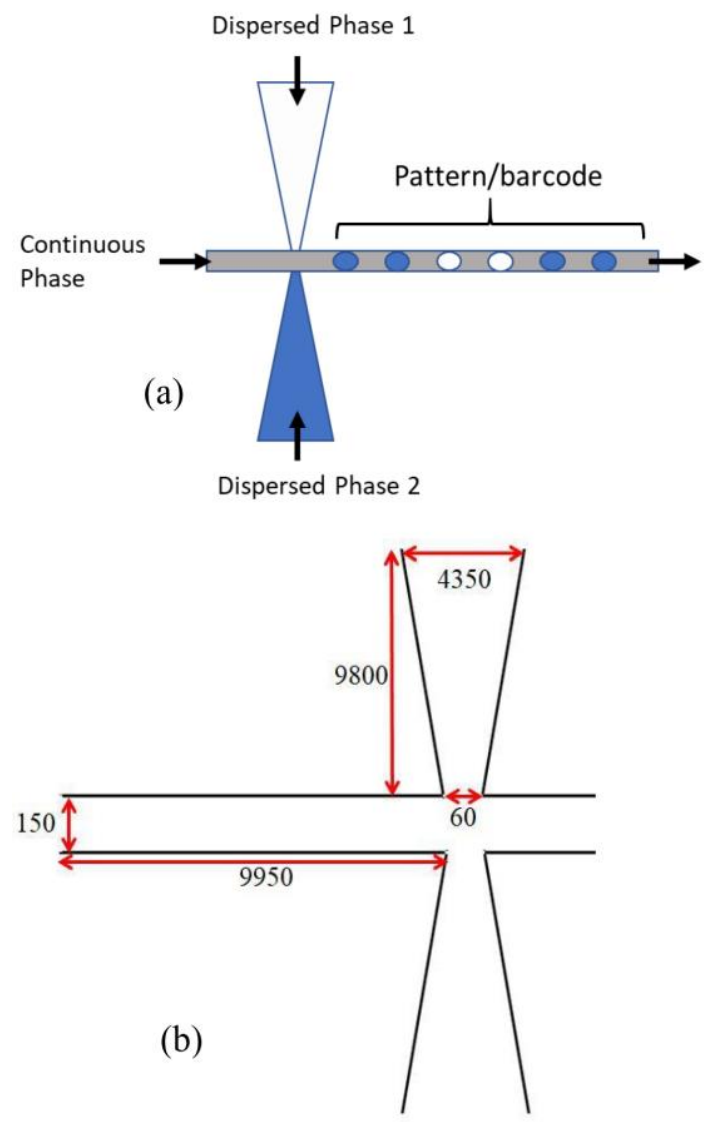

Figure 2. (a) Schematic of the microreactor used for pattern generation from two liquids with unequal viscosities, (b) Dimensions of the microfluidics device. All dimensions are in $\mu \mathrm{m}$. The device is symmetric about the main channel channel geometry ensures obtaining distinct pressure variation between two droplet phase streams, eventually enabling only one stream to generate a droplet at a time. In this device, alternating pattern of droplets with unequal viscosities were obtained. The schematic of this device is shown in Figure 2.

In the second microfluidic system, first, two fluids (water and glycerol solution) are merged, then a droplet is formed in an alternating fashion to obtain a pattern. Again, a tapered geometry is used for the inlet of the dispersed phases. The schematic of this design is shown in Figure 3.
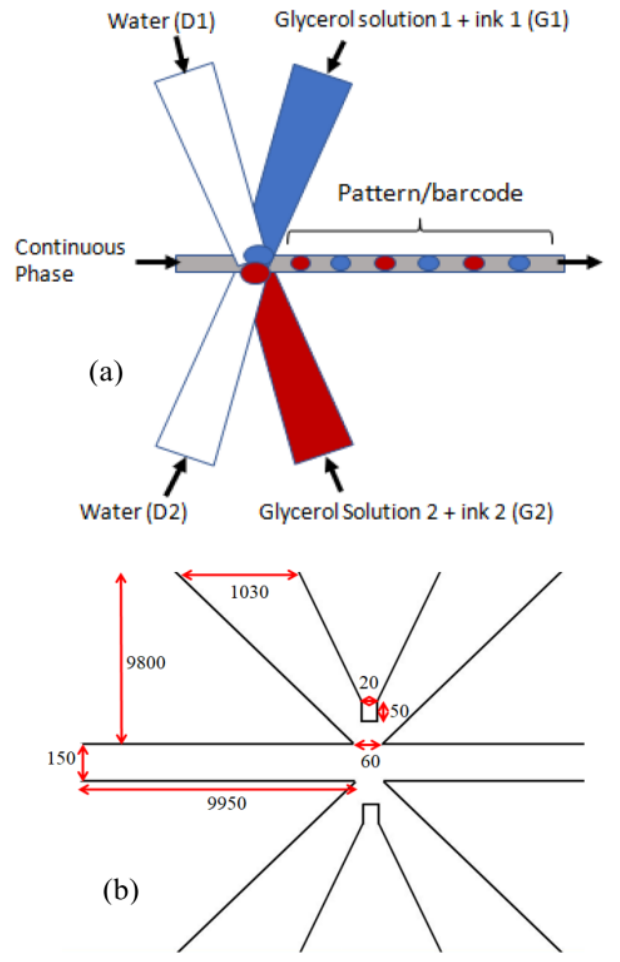

Figure 3. (a) Schematic of the microreactor used for pattern generation of droplets formed by mixing of two liquids. For the sake of identification dispersed phase streams have been labeled D1, D2, G1 and G2. (b) Dimensions of the microfluidics device. All dimensions are in $\mu \mathrm{m}$. The device is symmetric about the main channel and all dispersed phase channels are identical 


\section{RESULTS AND DISCUSSION}

For the droplet generation, the $\mathrm{Ca}$ number is calculated as shown below.

$\mathrm{Ca}=\frac{\mu \mathrm{U}}{\gamma}=7.94 \times 10^{-3}$

Where the values of viscosity $(\mu)$, speed $(U)$, crosssectional area $(\mathrm{A})$, continuous phase flow rate $\left(\mathrm{Q}_{\mathrm{c}}\right)$ and surface tension $(\gamma)$ are as follows:

$$
\begin{aligned}
& \mu=0.0562 \mathrm{Ns} / \mathrm{m}^{2}, A=1.49 \times 10^{-8} \mathrm{~m}^{3} / \mathrm{s}, \\
& Q_{c}=5.01 \times 10^{-11} \mathrm{~m}^{3} / \mathrm{s}, U=2.32 \times 10^{-3} \mathrm{~m} / \mathrm{s}, \\
& \gamma=1.642 \times 10^{-2} \mathrm{~N} / \mathrm{m} .
\end{aligned}
$$

Since the Ca number is of the order of $10^{-3}$, the interfacial forces are more dominant than shear forces because the droplet generation is in the squeezing regime [21]. As a result, the pressure distribution over the droplet governs the droplet generation mechanism instead of shear force applied by the continuous phase fluid.

The Bond number was calculated for this system, and since it is significantly less than 1, it may be reasonably inferred that gravitational forces have no effect.

The tapered geometry controls the Laplace pressure drop at the junction where droplets form; this is described in detail by Saqib et al [19]. When the liquid from one of the dispersed channel inlets enters the junction, the dispersed phase from the opposite side gets suppressed and does not enter the junction. By this way a controlled droplet sequence can be achieved.

In this study we demonstrate the formation of a droplet pattern by two liquids with different viscosities. Droplets are composed of water mixed with glycerol solution to obtain desired viscosities. In Figure $4 a$, a pattern with $2: 1$ ratio is formed. The viscosities of transparent dispersed phase 1 and blue dispersed phase 2 are $2.49 \mathrm{mPa} . \mathrm{s}$ and $1.0 \mathrm{mPa} . \mathrm{s}$ respectively. The pattern formation can also be adjusted to obtain droplets in 3:1 sequence as shown in Figure $4 \mathrm{~b}$. The solutions used in this study are mixed before they are delivered to the microchannels.

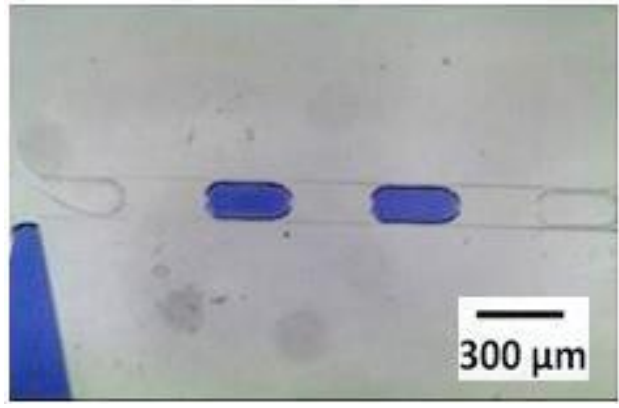

(a)

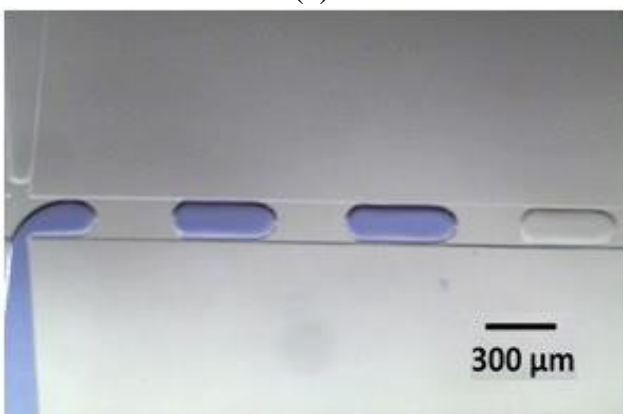

(b)

Figure 4. Pattern formation with liquids having different viscosities. (a) $2: 1$ ratio (b) $3: 1$ ratio. The dispersed phase 1 and the dispersed phase 2 have volumetric flow rates as $0.2 \mu \mathrm{l} / \mathrm{min}$ and 0.15 $\mu 1 /$ min respectively and the continuous phase flow rate is $2.0 \mu \mathrm{l} / \mathrm{min}$. Dispersed phase 2 contains food coloring as identification

In this study patterns of droplets that are formed after mixing two liquids on-chip are also demonstrated. Here, each droplet is formed by merging an aqueous glycerol solution and water to obtain desired viscosities. The glycerol solutions are dyed with ink in order to distinguish them. Figure 5 shows pattern formation with this method. At first, droplets 
with identical viscosities (3.71 $\mathrm{mPa} . \mathrm{s})$ are formed and a pattern was generated from droplets of opposing streams. Glycerol solution is dyed in order to follow the pattern. The $1: 1$ and $2: 1$ pattern formation are achieved (Figure 5a, 5b). Then patterns are formed by droplets having different viscosities. In this study the glycerol solution having the red dye is at a higher viscosity $(10.22 \mathrm{mPa} \cdot s)$ than the one with the black dye $(3.71 \mathrm{mPa} \cdot s)$. As this device supplies the advantage of mixing solutions in-situ, it is more practical when a series of droplets with content more than one type of liquid is needed. Figures $6 \mathrm{a}$ and $6 \mathrm{~b}$ show pattern formation in $1: 1$ and $2: 1$ ratio respectively for the different viscosity case.

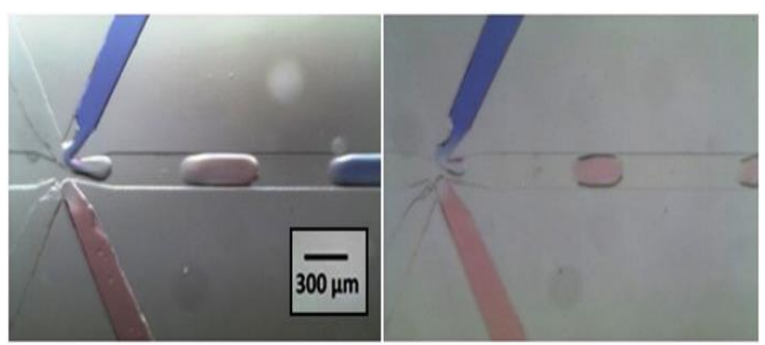

(a)

(b)

Figure 5. Droplet pattern formation with a mixing unit. (a) Droplets with identical viscosities are formed in a 1:1 alternating ratio. (b) Droplets with identical viscosities are formed in a $2: 1$ alternating ratio

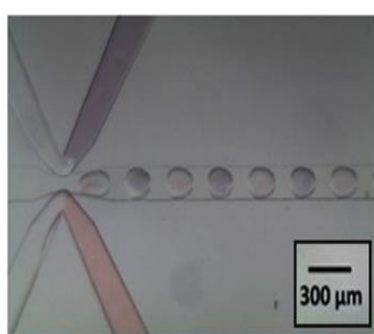

(a)

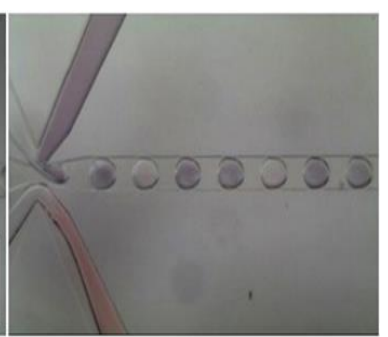

(b)
Figure 6. (a) Droplets with different viscosities are formed in a 1:1 alternating ratio. (b) Droplets with different viscosities are formed in a 2:1 alternating ratio

Droplet stream with higher viscosity (mixture of D2 and G2) requires higher shear force to be applied when forming droplets. Therefore, more droplets are generated from the less viscous phase (D1 and G1) in the pattern. Knowing this, the number of droplets from each stream can be controlled by flow rates.

A droplet forms when the net pressure imposed by the scattered phase is less than the pressure exerted in the upper stream (due to the continuous phase). The difference between the pressure in the scattered phase inlet channel and the Laplace pressure at the interface is the net pressure exerted by the dispersed phase. Hence we can determine the variation of pressure distribution at the junction by evaluating the Laplace pressure.

The graphical representation of the variation of the laplace pressure is developed by first measuring the radii of curvature of the dispersed phase streams from each side and then substituting these values into the formula for the Laplace pressure drop, given in equation (2), where $R_{T}$ is the radius of curvature of the tail of the droplet and $R_{H}$ is the radius of curvature of the head of the droplet.

$\Delta \mathrm{P}_{\mathrm{Lmax}}=\gamma\left(\frac{1}{\mathrm{R}_{\mathrm{Tc}}}-\frac{1}{\mathrm{R}_{\mathrm{Hc}}}\right)$

As it can be seen from the graph in Figure 7a, the case where droplets are generated in the ratio $1: 1$, the laplace pressure variation remains almost identical for each dispersed phase and therefore the opposing streams generate droplets one by one in a synchronized manner.

In the case where droplets are generated in the ratio 2:1, the less viscous mixture of D1 and G1 produce more droplets since they are at a higher flow rate and also since their mixture can be sheared with greater ease than the mixture of D2 and G2 that have a more viscous mixture. The variation of Laplace pressure, shown in Figure $7 \mathrm{~b}$, in this case further explains the droplet generation mechanism. When the mixture of D2 and G2 generate a droplet, the rate laplace pressure drop is very high since the mixture is more viscous. But when D1 and G1 generate a droplet the rate of laplace pressure drop is lower 
for the first drop which gives the opportunity to the second drop to be formed in a consecutive manner since D2 and G2 are still recovering from the laplace pressure drop from the previous droplet generation. In this way the dispersed phases keep alternating in a 2:1 ratio in a synchronized manner.
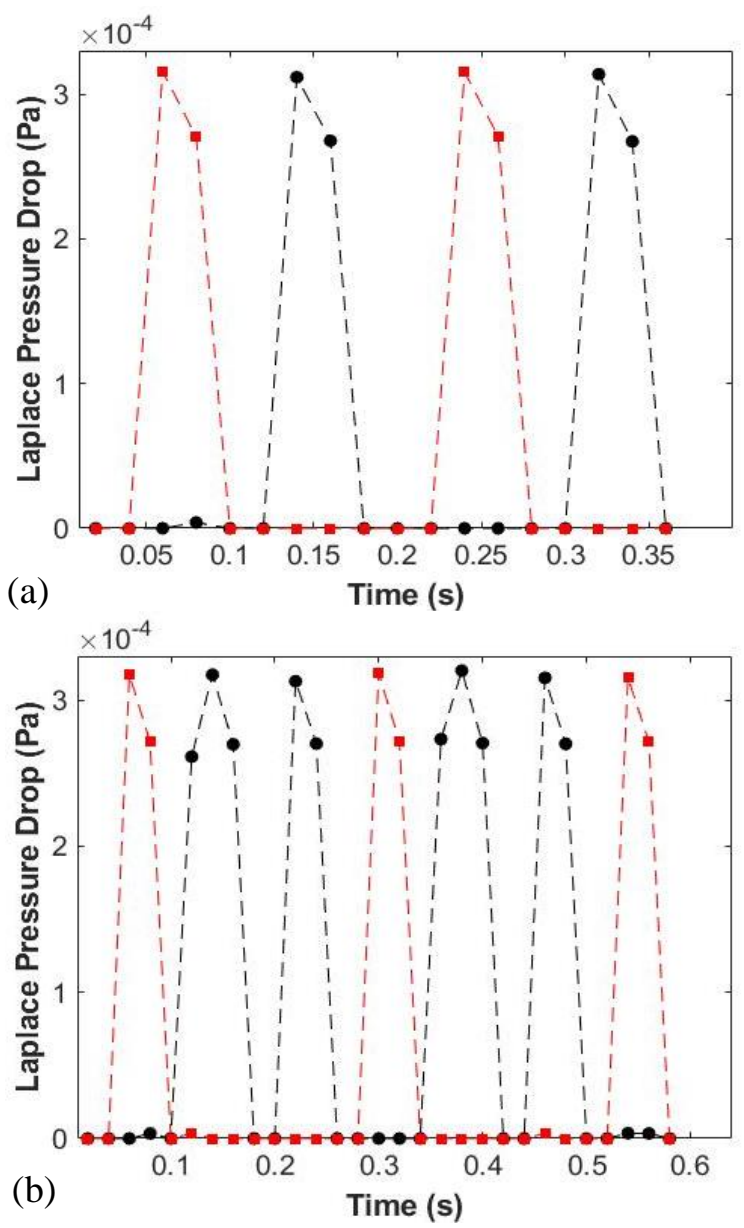

Figure 7. Laplace pressure drop of droplet phases at the junction. (a) In the case where droplets are formed in $1: 1$ ratio with continuous phase at $2.5 \mu \mathrm{L} / \mathrm{min}$, less viscous stream at $0.22 \mu \mathrm{L} / \mathrm{min}$ and high viscous stream at $0.3 \mu \mathrm{L} / \mathrm{min}$. (b) In the case where droplets are formed in $2: 1$ ratio. Flow rate of the continuous phase is $2.5 \mu \mathrm{L} / \mathrm{min}$, less viscous stream is at $0.35 \mu \mathrm{L} / \mathrm{min}$ and high viscous stream at $0.3 \mu \mathrm{L} / \mathrm{min}$

\section{CONCLUSION}

Pattern formation from droplets with different viscosities is demonstrated by using a tapered channel geometry. Forming droplets containing two different liquids within the same device is also achieved. This tool enables a device that can be used in monitoring or analysis of samples within droplets in a desired order. It also makes it possible to obtain a set of droplets carrying reagents to be merged at a later phase within the device for material synthesis in controlled concentrations. This device can also be used in applications where alternating droplet generation has to be achieved between fluids with significantly different viscosities specially in applications where some sort of marker has to be mixed with the dispersed phase just prior to droplet generation. Using Laplace pressure calculations obtained by utilizing the measured radii of curvature of the droplet during the droplet generation process, we infer how the alternation takes place for ratios 1:1 and 2:1.

\section{ACKNOWLEDGEMENT}

E.Y. Erdem would like to acknowledge the Tübitak for funding this work under the project number $115 \mathrm{~S} 112$.

\section{REFERENCES}

1. Guo, F., Lapsley, M.I., Nawaz, A.A., Zhaoö, Y., Lin, S.C.S., Chen, Y., Yang, S., Zhao, X. Z., Huang, T.J., 2012. A Droplet-based, Optofluidic Device for High-throughput, Quantitative Bioanalysis. Anal. Chem., 84(24), 10745-10749.

2. Brzeziński, M., Socka, M., Kost, B., 2019. Microfluidics for Producing Polylactide Nanoparticles and Microparticles and Their Drug Delivery Application. Polym. Int., 68(6), 997-1014.

3. Shembekar, N., Hu, H., Eustace, D., Merten, C.A., 2018. Single-cell Droplet Microfluidic Screening for Antibodies Specifically Binding to Target Cells. Cell Reports, 22(8), 2206-2215. 
4. Erdem, E.Y., Cheng, J.C., Doyle, F.M., Pisano, A.P., 2014. Multi-Temperature Zone, Droplet-based Microreactor for Increased Temperature Control in Nanoparticle Synthesis. Small, 10(6), 1076-1080.

5. Feng, H., Zheng, T., Li, M., Wu, J., Ji, H., Zhang, J., Zhao, W., Guo, J., 2019. Dropletbased Microfluidics Systems in Biomedical Applications. Electrophoresis, 40(11),1580-1590.

6. Özkan, A., Erdem, E.Y., 2015. Numerical Analysis of Mixing Performance in Sinusoidal Microchannels Based on Particle Motion in Droplets. Microfluidics and Nanofluidics, 19(5), 1101-1108.

7. Lashkaripour, A., Rodriguez, C., Ortiz, L., Densmore, D., 2019. Performance Tuning of Microfluidic Flow-focusing Droplet Generators. Lab Chip, 19, 1041-1053.

8. Rahimi, M., Shams Khorrami, A., Rezai P., 2019. Effect of Device Geometry on Droplet Size in Co-axial Flow-focusing Microfluidic Droplet Generation Devices. Colloid. Surf. A., 570, 510-517.

9. Chakraborty, I., Ricouvier, J., Yazhgur, P., Tabeling, P., Leshansky, A.M., 2019. Droplet Generation at Hele-shaw Microfluidic Tjunction. Physics of Fluids, 31, 022010.

10.Hong, J., Choi, M., Edel, J.B., deMello, A.J., 2010. Passive Self-synchronized Two-droplet Generation. Lab. Chip., 10, 2702-2709.

11.Zheng, B., Tice, J.D., Ismagilov, R.F., 2004. Formation of Droplets of Alternating Composition in Microfluidic Channels and Applications to Indexing of Concentrations in Droplet-based Assays. Anal. Chem., 76, 4977-4982.

12. Jin, B.J., Kim, Y.W., Lee, Y., Yoo, J.Y., 2010. Droplet Merging in a Straight Microchannel Using Droplet Size or Viscosity Difference. Journal of Micromechanics and Microengineering, 20(3), 035003.

13. Ngo, I.L., Woo Joo, S., Byon, C., 2016. Effects of Junction Angle and Viscosity Ratio on Droplet Formation in Microfluidic Cross-junction. Journal of Fluids Engineering, 138(5).

14. Han, W., Chen, X., Hu, Z., Yang, K., 2018. Three-dimensional Numerical Simulation of a Droplet Generation in a Double T-junction Microchannel. Journal of Micro/
Nanolithography, MEMS, and MOEMS, 17(2), 025502.

15. Yao, J., Lin, F., Kim, H.S., Park, J., 2019. The Effect of Oil Viscosity on Droplet Generation Rate and Droplet Size in a Tjunction Microfluidic Droplet Generator. Micromachines, 10(12), 808.

16.Zhang, Y.Y., Xia, H.M., Wu, J.W., Zhang, J., Wang, Z.P., 2019. Synchronized Generation and Coalescence of Largely Dissimilar Microdroplets Governed by Pulsating Continuous-phase Flow. Applied Physics Letters, 114(7), 073701.

17. Wu, J., Xia, H., Wang, W., Foo, Y., Wang, Z., Du, H., 2020. A Droplet Platform Capable of Handling Dissimilar Liquids and its Application for Separation of Bacteria from Blood. Biomicrofluidics, 14(3), 034102.

18. Surya, H.P.N., Parayil, S., Banerjee, U., Chander, S., Sen, A.K., 2015. Alternating and Merged Droplets in a Double T-junction Microchannel. Bio Chip J., 9, 16-26.

19. Saqib, M., Şahinoğlu, O.B., Erdem, E.Y., 2018. Alternating Droplet Formation by Using Tapered Channel Geometry. Sci. Rep., 8(1), 1-9.

20. Wahab, M.A., Erdem, E.Y., 2020. Multi-step Microfludic Reactor for the Synthesis of Hybrid Nanoparticles. J. Micromech. Microeng., 30(8), 085006.

21. Garstecki, P., Fuerstman, M.J., Stone, H.A., Whitesides, G.M., 2006. Formation of Droplets and Bubbles in a Microfluidic Tjunction-scaling and Mechanism of Break-up. Lab on a Chip, 6(3), 437-446. 